\title{
EL TRATADO DE LIBRE COMERCIO DE AMÉRICA DEL NORTE Y LAS DENOMINADAS "CARTAS PARALELAS"
}

\author{
Rodolfo CRUZ MIRAMONTES*
}

RESUMEN: A raíz de la diferencia surgida entre nuestro país y el vecino del norte en materia de edulcorantes y endulzantes, por las llamadas "cartas paralelas", las cuales fueron firmadas únicamente por los representantes comerciales de ese momento, Jaime Serra Puche y Mickey Kantor, y en donde se plantean algunas especificaciones al anexo 703.2 del TLCAN, relativas a los excedentes de producción. El autor plantea su validez legal, analizando, para esto, los sistemas de recepción del derecho internacional en ambos países, poniendo especial énfasis en los llamados Acuerdos Ejecutivos, y concluyendo la carencia de validez legal de estas cartas paralelas.

\begin{abstract}
Based on the difference that came out between our country and our Northern Neighbor in the mater of the sugar, and due to the "parallel letters" which were signed exclusively by the official commercial traders in that time, Mr. Jaime Serra Puche and Mr. Michey Kantor, where also some specifications were stated to the annex 703 from the NAFTA in reference to the over productions amount. The author is questioning the legal validity of this by analyzing the reception systems of the International Law of both countries, with an special emphasis on the executive agreements and concluding the lack of legal validity of such parallel letters.
\end{abstract}

* Doctor en derecho por la Universidad de Madrid. Profesor de derecho internacional público y de derecho del comercio internacional. Coordinador del sector industrial por la COECE en las negociaciones comerciales internacionales y de las mesas de Solución de Controversias y de Prácticas Desleales en el TLCAN, en el TLCUE y en los demás acuerdos comerciales internacionales suscritos por México. 
SUMARIO: I. Antecedentes. II. La negociación del TLCAN. III. La negociación del azúcar en el TLCAN y las "cartas paralelas". IV. La Convención de Viena sobre el Derecho de los Tratados de 1969. V. Estudio analítico y opinión sobre las "cartas paralelas”. VI. Conclusiones. VII. Bibliografía.

\section{ANTECEDENTES}

Recientemente se ha planteado una disputa entre los gobiernos de dos de las partes del TLCAN (México y los Estados Unidos) para definir sobre la aplicación del texto del tratado en la parte correspondiente al azúcar y a los edulcorantes o el contenido de dos documentos similares entre sí, que pretenden modificar la parte sustancial del mismo.

Con tal motivo, desde hace tiempo se han celebrado pláticas tendientes a evitar la controversia, pero no han prosperado, por lo que se acudió de manera formal al mecanismo contemplado en el capítulo XX del Acuerdo Trilateral en vigor desde 1994.

La sección "B" del Acuerdo se refiere, conforme a su título, a la "Solución de controversias"; ésta se inicia con un compromiso formal de las partes involucradas, de intentar una solución satisfactoria mediante las consultas y la "cooperación" (artículo 2003).

Conforme al citado mecanismo, cuando las partes resuelvan acudir al Acuerdo deberán acordar el foro para ventilar el asunto, dado que por ser miembros de la OMC tienen también la posibilidad de plantearlo en Ginebra, conforme al Entendimiento de Solución de Diferencias.

Las consultas del caso se harán por escrito, y se entregará una copia al Secretariado; deberán hacer "todo lo posible por alcanzar una solución mutuamente satisfactoria” (artículo 2006, p. 5).

En caso de que no prospere una consulta, cualquiera de los afectados podrá solicitar, después de transcurrido el plazo aplicable, que se reúna la Comisión.

En el escrito de petición la parte inconforme deberá consignar el tema de la reclamación y sus fundamentos legales; además, deberá turnar una copia al secretariado y a las partes.

En el caso mencionado transcurrió el plazo correspondiente y se pidió la reunión de la Comisión tal como se previene en el artículo 2007 en sus párrafos 1 , a) y 3 . 
Reunida la Comisión en el plazo de diez días y no habiéndose solucionado el diferendo en los términos consignados en el artículo 2008, párrafo 1 , a), se procedió a pedir la instalación de un panel conforme al párrafo 2 del mismo artículo 2008.

A partir del 17 de agosto del 2000 se inició el proceso arbitral de cuenta, por lo que oportunamente se instalará un tribunal que funcionará conforme a las disposiciones del capítulo XX, sección B, y de las Reglas Modelo de Procedimiento previstas en el artículo 2012. ${ }^{1}$

El Tribunal se compondrá de cinco panelistas, que serán seleccionados de la lista de treinta que oportunamente las partes conformaron en acatamiento a la obligación contenida en el artículo 2002.

Así, dentro de los 15 días siguientes a la petición de la instalación del panel, "Las partes contendientes procurarán acordar la designación del Presidente..." (artículo 2011, 1, b), lo que debió suceder a más tardar el 7 de septiembre conforme a la regla 2 , que enlista los días considerados inhábiles en los tres países, por lo que los demás serán hábiles.

La formación del panel, como cualquier otro de los considerados en el TLCAN, no es fácil, pues al no existir un tribunal permanente (tal como lo sugerimos durante las negociaciones del Tratado, ${ }^{2}$ cada vez se debe acudir a la disponibilidad de las personas enlistadas y a su aceptación, además de que no existan condiciones que les provoquen incompatibilidad en el asunto a estudiar.

Por ello no podemos vislumbrar un término cierto, sino hasta que no se constituya. Aun después de ese momento los términos para dictar los informes previos y definitivos quedarán sujetos a que durante la tramitación del proceso no surjan acontecimientos que dilaten su ejercicio.

Hasta ahora no se ha dado a conocer públicamente si ya se avanzó en la constitución del panel, por lo que inferimos que está en proceso de formarse.

Tampoco se conoce con certeza cuál será el tema o los puntos de queja del gobierno mexicano que lo llevaron a decidirse a iniciar este proceso.

Sin embargo, en diversas ocasiones, la Secretaría de Comercio y Fomento Industrial (SECOFI), a través de sus más altos funcionarios, ha ex-

1 Reglas Modelo de Procedimiento del capítulo XX del TLCAN. No han sido publicadas a la fecha en el Diario Oficial de la Federación. Pueden consultarse en la página web del Secretariado del TLCAN: http//www.nafta-sec-alena.org/spanish/rules/ch20/ch20p. htm.

2 Cruz Miramontes, Roddolfo, "Rechaza Washington la propuesta mexicana sobre la formación de un Tribunal Comercial, R. Cruz", El Financiero, México, 6 de marzo de 1992. 
presado que ante la falta de una legítima expectativa de obtener un mayor volumen de azúcar dentro del sistema de cuota al mercado norteamericano que le ha producido menoscabo en sus derechos, le ha hecho temer que no se cumplan las obligaciones contenidas en el Anexo $703.2 \mathrm{del}$ TLCAN, cuyos párrafos 15 y 16 regulan el acceso del producto.

Por ende, desde el 12 de marzo de 1998 se plantearon las consultas de referencia sin lograr resultado alguno, pues su contraparte alega que dichos compromisos se modificaron por las susodichas "cartas paralelas". 3

Sirviendo los comentarios y datos anteriores como antecedentes, pasaremos ahora a estimar diversos aspectos jurídicos del caso, bajo el supuesto de que dichas cartas fueron celebradas y firmadas, y así valorar su efecto jurídico en el TLCAN.

Para comprender debidamente el problema, estimo útil mencionar algunos datos que giran en torno al tema del azúcar y dan razón del porqué de las susodichas "cartas paralelas".

\section{LA NEGOCIACIÓN DEL TLCAN}

El Tratado de Libre Comercio de América del Norte (TLCAN) constituye un instrumento jurídico-económico de gran envergadura y ambición, pues rebasa con mucho los parámetros tradicionales de una zona de libre comercio, ya que abarca tanto la totalidad de los aranceles comerciales, establece criterios y controles a las barreras no arancelarias, y permite que se concierten múltiples disciplinas a las inversiones, a los servicios, a la propiedad intelectual, con lo cual se crea todo un arsenal de mecanismos, sistemas y criterios que buscan prevenir y resolver los conflictos lógicos que surgen en todo acuerdo internacional. ${ }^{4}$

La existencia de desavenencias y roces por la aplicación del Tratado es natural y es parte de su propia existencia, por lo que en mi opinión fue loable que se previnieran y se dieran remedios, pues solamente así se puede esperar su éxito.

Como señalamos, la magnitud y ambición del Acuerdo es completa y universal; no "comprensivo", como torpemente se le califica, pues la

3 Hall, Kevin G., "U.S and Mexico attempt to resolve sugar dispute", The Journal of Commerce, EUA, marzo 20 de 1998. "Mexico may seek NAFTA panel on sugar Dispute with US, DowJones News Wires", 9 de agosto de 1999.

4 Para un mayor conocimiento ver, entre otros, Cruz Miramontes, Rodolfo, El TLC: controversias, soluciones y otros temas conexos, México, McGraw-Hill, 1997. 
comprensión es una cualidad del hombre. Se utiliza equivocadamente la expresión inglesa de "comprehensive" para significar que todo está incluido.

De paso diremos que esta grave deficiencia es una de las muchas que constituyen un atropello a nuestro idioma. Quienes participamos en las negociaciones desde la trinchera del sector privado no logramos que se corrigieran todas las fallas detectadas.

Se planteó originalmente entre los Estados Unidos Mexicanos, promoventes del Tratado, y los Estados Unidos de América; posteriormente, el 5 de febrero de $1991^{5}$ Canadá resolvió unirse, pues ya tenía establecida una zona de libre comercio desde 1989 con su vecino, a través del Free Trade Agreement (FTA), lo que era lógico sucediera.

Después de intensas y arduas negociaciones que empezadas el 12 de junio de 1991 en Toronto, Canadá, concluyeron el 12 de agosto de 1992, en Washington.

Los temas tratados fueron numerosos, pero giraron en torno a seis grandes conceptos que se subdividieron en varios temas variables, pues de alguna forma se fueron ajustando según las circunstancias lo exigían, y así a veces eran 23 y otras menos, terminando en 19.

Cuando se informaba de los avances de las mesas de trabajo, el sector privado, que tuvo una participación notable tanto durante la preparación de los trabajos (se elaboraron 174 monografías) como durante las pláticas a través del "cuarto de junto", siempre añadía un tema más, como fue el de las prácticas desleales de comercio (antidumping y subsidios), pues las contrapartes se negaban a tratarlo.

Gracias a nuestra tozudez y constancia logramos que en abril de 1992 se incorporara dentro del tema de "Reglas de Comercio", y así obtuvimos el capítulo XIX, similar al 19 del FTA, cuya presencia era básica, al grado de que sin él, el TLCAN era cuestionable, como lo manifesté públicamente. ${ }^{6}$

5 El 21 de agosto de 1990 el presidente de México envió una carta a su homólogo norteamericano proponiendo la negociación del Tratado. Para conocer los pasos previos y los que se dieron durante la negociación, se sugiere consultar: Von Bertrab, Hermann, El redescrubrimiento de América. Historia del TLC, México, Fondo de Cultura Económica, 1996. Asimismo: Garciadiego, Javier et al., El TLC día a día, México, Miguel Ángel Porrúa, 1994.

6 El Financiero, México, 6 de marzo de 1992: “El ex presidente de la Cámara Nacional de la Industria del Cemento comenta que si no se consigue acordar un mecanismo que elimine la discrecionalidad y la inequidad a la hora de dirimir controversias, la esencia misma del TLCAN quedaría en entredicho". 
Al término de la jornada, el 17 de diciembre de 1992, el texto fue firmado y se inició el proceso de ratificación por los respectivos poderes legislativos.

Obviamente, el norteamericano fue muy desgastante; los ataques a México en los medios y en los debates fueron despiadados, y no faltaron insultos sin medida.

Tocó que se planteara en plenas elecciones presidenciales y que hubiera relevo presidencial y de partido político, lo que creó una atmósfera tormentosa alrededor del Congreso norteamericano.

El procedimiento seguido es excepcional, pues está sujeto al llamado fast track establecido en la Trade Act of 1974 y desarrollado en la Trade Negociating Authority Provisions of the Omnibus Trade and Competitiveness Act of 1988 (P.L. 100-418 Secc. 1102).

Esto significa que los tratados sobre temas comerciales que toquen los aranceles podrán, en razón de su importancia y oportunidad, sustraerse del tratamiento propio de los acuerdos ordinarios conforme al artículo II, sección 2, párrafo 2, de la Constitución, y no pasar por el Senado y tampoco sufrir modificaciones. Tendrán en cambio que ser conocidos por el Congreso a través de sus dos Cámaras y ser aprobados en su integridad o rechazados (los votos sólo se expresarán yeah o neah).

Se prevén plazos determinados para su tramitación, los que son perentorios.

El TLCAN tuvo otra presión muy fuerte agravada por el hecho de que no contaba con gran simpatía, y los opositores eran poderosos.

Adicionalmente sucedió que los sectores privados norteamericano y canadiense no estuvieron cerca del proceso negociador, como sucedió en México y no tuvieron ni la capacidad ni la imaginación de crear una COECE (Coordinadora Empresarial de Comercio Exterior).

Por ello, en la medida en que fue trasminándose el texto de lo acordado surgieron gestiones en contra o, al menos, pretensiones de reformas.

Para ello se jugó con el voto de los congresistas presionados por sus representados.

Esto motivó un proceso muy complejo y acciones múltiples, en donde el Ejecutivo tuvo que concertar compromisos muy diversos, desde prebendas políticas, apoyos económicos y la suscripción de ciertos acuerdos laterales al Tratado.

En este punto entra el tema de las "cartas paralelas". 
Para entender su condición será necesario tener presente que el sistema administrativo norteamericano es muy complejo entre su filosofía de pesos y contrapesos y su espíritu pragmático que tienen todas sus acciones.

Los tratados internacionales, siendo facultad negociadora original del Ejecutivo y aprobatoria del Senado, han sufrido desde hace muchos años fisuras que admiten la presencia de acuerdos simplificados que sólo puede llevar a cabo el Ejecutivo sin la presencia reguladora del otro poder.

Con el tiempo se han venido produciendo cambios, y así originalmente se ocupaban de temas de relaciones de paz, de reclamaciones y de compensaciones y reconocimiento de gobiernos y otros; posteriormente han ampliado su campo y han llegado a comprender inclusive al tema comercial, lo que es delicado.

La pugna entre los dos poderes es muy fuerte desde que surgió el país como Estado sobrerano. El Ejecutivo siempre busca el control del poder político y el Legislativo trata de limitárselo.

Por ende, el TLCAN no fue una excepción, y menos podría serlo dada su trascendencia.

La negociación de aspectos comerciales que afecten a los aranceles es facultad exclusiva del Congreso (artículo 1o., sección 8, párrafo 3 de la Constitución), y para modificarlos se requiere una autorización expresa de ese órgano. Como no es fácil prever cuáles y cuántos serán afectados, se inventó el fast track, y así poder controlar de esta forma las gestiones comerciales internacionales del presidente sin afectar el aspecto comercial.

Al aproximarse la fecha tope de la presentación del texto del tratado y de los proyectos legislativos para su implementación, se armó todo un paquete de documentos y de otros acuerdos que habían surgido de las componendas múltiples para acarrearse los votos necesarios y lograr su aprobación. ${ }^{7}$

En el momento preciso se obtuvieron 234 votos a favor y 200 en contra de la Cámara de Representantes el 17 de noviembre, y de 61 a 38, respectivamente, de la de Senadores el 20 de noviembre de 1993, y así quedó aprobado en definitiva.

7 Hermann von Bertrab, que estuvo inmerso en el proceso como encargado de la oficina del TLCAN en Washington, D.C., nos da pormenores de lo sucedido, ver Von Bertrab, Hermann, op. cit., nota 5, pp. 210-254. Asimismo, consultar, entre otros, Posadas, Alejandro, "NAFTA'S Approval: A Story of Congress at Work...", LSA Journal of International and Comparatives Law, EUA, vol. 2, núm. 2, primavera de 1996. 
Es notable la forma en que el presidente Clinton (quien tomó posesión en enero de ese año) laboró para apoyar lo hecho por su antecesor del Partido Republicano, contrario al suyo, y más aún, singular la forma en que presentó el asunto al Congreso.

El 4 de noviembre lo hizo, pero separó en dos momentos distintos su presentación. En una primera compuso un paquete con el texto del tratado, la llamada Statement of Administrative Action, y cierta información de apoyo (H.R. 3450). La carta de envío está fechada el 3 de noviembre.

Un segundo paquete enviado al Congreso por la Casa Blanca el mismo 4 de noviembre se componía de una carta explicativa del presidente W. Clinton firmada en esa fecha, y de los siguientes documentos por el orden en que fueron anexados:

1. Los acuerdos suplementarios o paralelos relativos al medio ambiente, a cuestiones laborales y a la importación desmedida e inusitada de bienes.

2. Acuerdos relativos a cítricos, azúcar y edulcorantes celebrados con México.

3. Acuerdo sobre el fondo de apoyo al desarrollo fronterizo, celebrado con México.

4. Cartas relativas a la desgravación acelerada prevista en el texto del tratado.

5. Informe sobre la situación ambiental y acuerdos laterales.

6. Lista de documentos e informes enviados al Congreso durante la negociación del TLCAN.

Si bien la razón que tuvo el presidente norteamericano para buscar, a través de múltiples maniobras políticas y de prebendas personales, el voto favorable, es clara desde el ángulo de la política interna norteamericana, no lo es tanto para los otros dos signatarios. ${ }^{8}$

Como veremos más adelante, se deslavaron algunos magníficos logros de los negociadores mexicanos, y tal vez de los canadienses en el tema del trigo, por ejemplo, pero también es cierto que algunos acuerdos completaron al principal, y que además en otros como en salvaguardas, estuvieron bien. Otros más no tuvieron mayores efectos al momento,

8 "Many of the deals were formalized through letters of understanding, but others were the product of unwritten political compromises", nos dice el Lic. Alejandro Posadas, op. cit., nota 7 , p. 443 . 
como la carta invitando a que a partir de la entrada en vigor del TLCAN se sentasen a negociar la desgravación acelerada tal como estaba previsto en el artículo 302, párrafo 3o., del mismo.

\section{LA NEGOCIACIÓN DEL AZÚCAR EN EL TLCAN Y LAS "CARTAS PARALELAS"}

Sin referirme detalladamente a las negociaciones, me ocuparé básicamente de los resultados obtenidos y de algunos elementos que giraron en torno a ellas.

En su momento tenemos que México, productor de azúcar de caña desde finales del siglo XVI, satisfacía apenas la demanda interna a inicios de los noventa, e inclusive había tenido que importar el producto, lo que provocó algunos problemas graves a la industria.

Por ende, al iniciarse las negociaciones el 12 de junio de 1991, la posición de la industria era conservadora y no agresiva.

Los Estados Unidos a la vez eran y siguen siendo deficitarios y han establecido un sistema de arancel cuota desde 1990 a raíz de un caso resuelto en su contra que fue planteado por Australia ante el GATT, mediante el cual surten sus faltantes otorgando a determinados países, de manera graciosa, un cupo de acceso con un arancel mínimo casi " 0 ", por lo que el precio regido por la demanda es siempre atractivo.

En cambio, el mercado internacional generalmente ofrece precios muy bajos, pues la oferta es mayor a la demanda.

Otros mercados regionales ofrecen poco atractivo, pues los sistemas que los controlan protegen a sus productores, como sucede en la Unión Europea.

Al finalizar la Ronda Uruguay, los Estados Unidos se comprometieron con la OMC a importar un mínimo de 1'250,000 toneladas métricas anuales asignables a sus proveedores habituales conforme diversos criterios: los antecedentes históricos como proveedor, su relación "diplomática", o bien otras consideraciones.

Por lo dicho, al momento de las negociaciones México no era proveedor, y por ello se le ubicó en una categoría mínima de entrada (7,258 tm.), pero se diseñó un sistema propio que sólo rige en el tema entre los Estados Unidos y México. 
El Anexo 703.2 se ocupa de ello y establece que habrá una desgravación gradual en dos fases: una lenta durante los primeros seis años y una acelerada hasta llegar a " 0 ” a los quince años de vida del Tratado.

Además, se acordaron parámetros precisos e hipótesis a satisfacer.

Por lo tanto, de inicio se contó con la cuota mínima indicada, que podría llegar anualmente a un máximo de 25,000 toneladas métricas de azúcar cruda.

Dicho monto se incrementará al séptimo año comercial a 150,000 toneladas métricas valor crudo (párrafo 15 , incisos a) y b)), y se añadirán $110 \%$ de aumento anual hasta el año 2007, pues a partir del siguiente la tasa sería " 0 " contados a partir de la fecha de entrada en vigor de este Tratado.

Sin embargo, esta situación podría cambiar drásticamente, si resultara que México, como parte exportadora, lograse ser superavitario por dos años consecutivos "...a partir de la fecha de entrada en vigor de este Tratado", tal como reza el inciso a) del párrafo 16 del Anexo en cuestión.

Dicho cálculo deberá hacerse sobre la situación del año comercial previo y el que corre con alguna alternativa que no cambia el concepto (incisos b) y c) del mismo Anexo).

Como se desprende, tal situación consideró sin duda que México tardaría en ser superavitario, pues su producción no alcanzaba los cuatro millones de toneladas, y la demanda era similar.

Al divulgarse el citado texto, posiblemente los productores norteamericanos se enteraron y consideraron que si bien la fórmula era cómoda, podría suceder sin embargo que pronto llegase a operar, pues arribaría a ser superavitario no sólo con base en sus zafras, sino en que el jarabe de maíz de alta fructosa, al no tener controles de acceso al mercado mexicano, desplazaría al azúcar de los usuarios tradicionales por ser un producto similar. En los Estados Unidos se dio el fenómeno en varias ramas industriales, que provocó un serio descalabro a los azucareros domésticos.

El hecho era fácilmente previsible, no sólo por el antecedente histórico mencionado, sino porque los propios productores norteamericanos de fructosa lo anunciaron y la ampliación de sus plantas lo evidenciaron al no requerirse por falta de demanda interna.

No faltó además quien pensara, y no sin base, por darse el caso en países no productores de azúcar, que México podría comprar el bien a bajo precio en Cuba y llevarla al mercado norteamericano. ${ }^{9}$ 
Por ello, desde el mes de junio de 1993 el representante comercial de los Estados Unidos de América (USTR), Mickey Kantor, planteó su preocupación a su homólogo mexicano, y después de cruzarse varias propuestas se arribó a una fórmula que aparentemente les satisfizo.

El texto de la misma se plasmó en las famosas cartas a las que el presidente Clinton se refirió en el segundo paquete de documentos enviado a su Congreso el 4 de noviembre, como ya quedó dicho.

En un documento relativo al TLCAN publicado por el Congreso y particularmente por la Cámara de Representantes bajo el N 103-160, titulado "Message from the President of the United States, transmitting North America Free Trade Agreement, Supplemental Agreements and Additional Documents" el 4 de noviembre (U.S. Government Printing Office, Washington, 1993), se incluye una copia impresa de dos cartas dirigidas por el señor M. Kantor al doctor Jaime Serra Puche como secretario de Comercio y Fomento Industrial, la una, y la otra de este segundo funcionario a su homólogo Kantor.

En ella se confirma el acuerdo, o sea simplemente la concurrencia de voluntades, alcanzado entre ambas representaciones relacionado con la implementación del Anexo 703.2 del TLC.

Particularmente se menciona lo relativo al intercambio de azúcares y jarabes ("sugar and syrup goods") y al compromiso adquirido cuando alguno de los países sea o se estime que pueda ser superavitario; por tal se considerará cuando tenga "un excedente de producción neto".

Tendrá este carácter cuando dicho excedente de producción de azúcar sea superior a su consumo total de azúcar durante un año comercial.

Sin embargo, se establece que dado que la fructosa "...puede substituir fácilmente a los azúcares..." podrían presentarse situaciones "no deseadas".

Por ello, la fórmula para calcular si se es o no superavitario cambiará y considerará no sólo el azúcar, sino a la fructosa de maíz, lo que también provoca una cuestión, dada la redacción del párrafo en cada una de las misivas cruzadas.

En la carta de Kantor, al finalizar el párrafo cuarto dice textualmente: “...The determination of 'net production surplus' for purposes of Section A of Annex 703.2 shall include consumption of high fructose corn syrup..."

Serra Puche, en la misma parte de su comunicado, que es prácticamente igual, elimina la palabra "consumption", por lo que hace mayor congruencia con el concepto a definir, o sea: "excedente de producción neta". 
Por otra parte, se modifica el párrafo 15 en sus incisos b) y c), determinándose el límite para los años séptimo al decimocuarto, en 250,000 toneladas métricas valor crudo y “...no se aplicará el párrafo 16 de la sección A del Anexo 703.2”.

Los productos en cuestión son los comprendidos en las fracciones 1702.40, 1702.50 y 1702.60 .

Dichas cartas, con las salvedades anotadas, pretenden modificar válidamente el texto mismo del TLCAN en la parte correspondiente, y la interpretación que se le ha querido dar es que constituyen una especie de segundo tratado, o dicho de otra forma, es una especie de "tratadito".

Según mencionamos, las cartas fueron incluidas en un segundo paquete de documentos presentados al Congreso en apoyo al TLCAN, en donde se mezclaron los calificados por la Casa Blanca como "Supplemental Agreements" con otros documentos adicionales.

En forma expresa los primeros están compuestos de los convenios sobre temas laborales, de protección al ambiente y de importaciones desmedidas, y los segundos, del resto de comunicaciones relacionadas, entre las que se incluyen a las cartas paralelas del azúcar y edulcorantes.

El presidente Clinton expresamente manifiesta que estos documentos adicionales no requieren aprobación formal del Congreso conforme al procedimiento del fast track, pero dado que ofrecen notables beneficios al pueblo norteamericano, el TLCAN deberá aprobarse para que operen.

Esta distinción no es fortuita ni obedece a un acto de ordenación del Ejecutivo; tiene una razón más de fondo de carácter jurídico y político.

Para entender este tema será necesario referirnos a la distinción que el sistema norteamericano hace de los distintos tipos de acuerdos y compromisos internacionales que el presidente norteamericano y el Poder Ejecutivo a su cargo pueden efectuar.

\section{Los distintos acuerdos internacionales que el gobierno}

norteamericano puede celebrar

De inicio advertimos que la facultad de negociar los acuerdos internacionales está depositada en el presidente, pero con la asesoría y consentimiento del Senado, pero desde los inicios del país como entidad independiente se celebraron acuerdos directos sin la concurrencia del otro poder. Se atribuye su origen a un capricho del presidente Washington. 
A través del ejercicio de esta actividad se pueden distinguir, conforme a la opinión de algunos autores consultados, los siguientes:

1. Los acuerdos tradicionales negociados por el Ejecutivo y aprobados por el Senado contemplados en el artículo II, sección 2, párrafo 2, de la Constitución, denominados "tratados senatoriales".

2. Los acuerdos ejecutivos congresionales, que pueden ser de dos tipos:
A) Los que reciben una autorización previa del Poder Legislativo para negociarse.
B) Aquellos que una vez negociados se envían al Congreso para su aprobación con efectos retroactivos.

3. Los acuerdos llevados a cabo únicamente por el presidente conocidos como presidential-executive o sole executive agreements.

4. Los denominados por algunos autores europeos como gentleman agreements, de singular importancia a finales de la Segunda Guerra Mundial. ${ }^{10}$

5. Por último, se quiere por algunos estudiosos,${ }^{11}$ distinguir otra categoría en aquellos acuerdos que surgen en cumplimiento de un tratado.

Tal vez se refieran a los tratados que una vez aprobados por el Senado exigen la celebración de posteriores convenios para precisar ciertos detalles en su implementación, de tal manera que se refieren a acuerdos derivados o suplementarios que no constituyen en sí convenios independientes (treaty executive agreements).

Como fuere, la celebración de estos acuerdos ejecutivos se desprende, conforme sus apoyadores, en una facultad "inherente" al poder Ejecutivo, y particularmente a la autoridad constitucional del presidente, como lo señala el profesor John H. Jackson, quien constituye una de las máximas autoridades en los aspectos legales del comercio internacional en los Estados Unidos. ${ }^{12}$

10 Esta identificación la encontramos en Rousseau, Charles, Derecho internacional público, Barcelona, Ariel, 1961, pp. 25 y 39.

11 El profesor Alonso Gómez Robledo en su interesante estudio "Aproximaciones al marco jurídico internacional”, en Witker, Jorge (coord.), El Tratado de Libre Comercio de América del Norte. Analisis, diagnóstico y propuestas jurídicos, México, Instituto de Investigaciones Jurídicas, UNAM, 1993, t. I, p. 67, cita al profesor Oliver T. Covey, quien formula esta curiosa distinción.

12 Jackson, John H. et al., Legal Problems of International Economic Relations, 3a. ed., West Publishing, 1995, p. 118. 
Ante el incremento de estos acuerdos simplificados se ha ido agudizando la pugna entre quienes defienden la cláusula de los tratados, que confiere al Senado la facultad de asesorar y autorizar por mayoría de dos terceras partes (treaty clause) la celebración de tratados versus quienes apoyan la negociación de acuerdos internacionales por el presidente sin la intervención del Senado, o bien, eventualmente del Congreso de manera muy limitada.

En la práctica tenemos casos de gran importancia a nivel mundial que ha firmado el Poder Ejecutivo sin dar participación al Senado calificados inclusive como "secretos", tal como fue el de los Acuerdos de Yalta del 11 de febrero de 1945, en donde se traspasaron a la Unión Soviética las islas Kuriles y la parte meridional de Sakhalin extralimitando las facultades militares del presidente. ${ }^{13}$

Según los datos recabados, de 1933 a 1940 se llevaron a cabo 105 tratados y 123 acuerdos ejecutivos; de 1945 a 1952, 132 tratados y 7,324 acuerdos ejecutivos (se incrementaron poco más de diez veces en ocho años), en el siguiente periodo presidencial, que sólo fue de cuatro años, el dato es de 63 tratados contra 846 acuerdos ejecutivos, y en los siguientes años la tendencia ha sido la misma.

Evidentemente, el conflicto entre los dos poderes, entre el Senado y el Ejecutivo y el mecanismo de participación colegiada del Legislativo y el Ejecutivo no se constriñe al interés meramente interno, sino que afecta seriamente a todos aquellos países con quienes se lleven a cabo negociaciones internacionales, y más específicamente de índole comercial, incluso a nivel multilateral, como es el caso de la Organización Mundial de Comercio.

La causa de la preocupación radica en el hecho de que la fuerza obligatoria interna de dichos acuerdos es distinta, pues en el caso de los tratados senatoriales no hay duda de que es absoluta; se convierte en la norma obligatoria conforme la tesis de que: "international law is the law of the land" (el derecho internacional es derecho propio) (artículo VI de la Constitución).

Empero, aquellos acuerdos que no son aprobados por las dos terceras partes del Senado presentan múltiples facetas de dificultad, y su repercusión interna puede ser distinta, pero sobre todo frente al país con quien se lleva a cabo el Acuerdo. ${ }^{14}$

13 Rousseau, Charles, op. cit., nota 10, p. 39.

14 La Suprema Corte ha ido encauzando y fijando de alguna manera, en casos relevantes, esta práctica del Ejecutivo, calificando a estos convenios como carentes de "dignidad" al no tener la apro- 
Si se parte de la premisa de que el presidente y las ramas del Ejecutivo pueden negociar cualquier tema en cualquier momento, el punto está en precisar si lo que se haga será necesariamente obligatorio y vinculante.

Otro tema a considerar necesariamente será la materia de que se trate, particularmente si concierne al comercio internacional y a los aranceles.

Por ello, desde que se anunció la posibilidad de negociar un acuerdo de libre comercio con dicho país manifestamos nuestras inquietudes al respecto, máxime que para México el tratado sería ley suprema, sólo un escaño abajo de la Constitución, ${ }^{15}$ que se aplicaría directamente al ser promulgada.

El Tratado de Libre Comercio de América del Norte (TLCAN) se ubica, conforme a la clasificación citada, entre los acuerdos ejecutivos congresionales que por haberse sujetado al sistema de la vía rápida (fast track), recibió una autorización previa a su negociación, por ello, se constriñó a un término de duración para ella y a una aprobación posterior, tal como se estipuló en la ley identificada como P.L. 100-418, sección 102, y el término consignado fue del 1 de mayo de 1991 al 31 de mayo de 1993; esto significa que la autoridad presidencial para negociarlo concluyó en esa fecha.

Adicionalmente debería, tal como aconteció, presentarse junto al texto del tratado y en el correspondiente término, una ley especial en la que conste su aprobación y su implementación (con base en las secciones 1103 y 102 de la Omnibus Trade and Competitiveness Act of 1988, que otorga al presidente las facultades legales para celebrarlo).

De cualquier manera, el TLCAN fue negociado válidamente, y quienes actuaron en representación del gobierno estadounidense sabían qué clase de compromiso iban a celebrar, y sin duda tuvieron en cuenta los "nueve mandamientos" que contienen las líneas generales que se deben observar, a juicio del Departamento de Estado equivalente a nuestra Secretaría de Relaciones Exteriores, contenidas en un manual emitido por la circular núm. 175, que obligan, sin importar qué clase de acuerdo se negociará, a formularse las siguientes, según la sección 711.3:

bación del Senado. Fisher, Louis, American Constitutional Law, Georgetown University, McGraw Hill, 1995, p. 362.

15 Cruz Miramontes, Rodolfo, "Entorno jurídico del TLC", Panorama jurídico del Tratado de Libre Comercio, México, Universidad Iberoamericana, Departamento de Derecho, 1993, t. II. 
- Consideraciones para seleccionar los procedimientos constitucionales permitidos, debiéndose tomar en cuenta los factores pertinentes junto con otros elementos constitucionales.

- La amplitud de los compromisos y factores de riesgos que asumirá el país y la nación en su totalidad.

- Hasta dónde se afectarán las leyes de los Estados, si fuere el caso.

- Si el futuro convenio podrá ponerse en marcha sin necesidad de que el Congreso promulgue alguna ley.

- Si existe algún antecedente o práctica sobre estos acuerdos.

- Si el Congreso ha manifestado alguna inclinación sobre la clase de acuerdo, en casos similares.

- El grado de formalidad deseado en la celebración del Acuerdo.

- En cuanto a su duración, cuál deberá ser la deseada, la necesidad de que concluya a la brevedad y la preferencia de que sea en un término ordinario o a corto plazo.

- En la determinación de qué clase de convenio deberá seleccionarse, será muy importante tomar en cuenta que se evitará afectar las facultades constitucionales del Senado, del Congreso como tal o del presidente.

- Se recomienda, por último, consultar con las comisiones competentes del Congreso.

Éstas eran las directrices prevalentes al menos hasta 1985.

Como podemos colegir, al Departamento de Estado le preocupa más que la profundidad y extensión del compromiso internacional, valorar los efectos internos y las posibles repercusiones a los poderes estatales.

\section{Los compromisos internacionales y su asunción conforme al derecho mexicano}

A continuación revisaremos cuál es el marco jurídico correspondiente al mismo tema, conforme al derecho mexicano.

Tradicionalmente se había considerado con base en la Constitución Política vigente, la existencia de los tratados internacionales debidamente negociados por quien tiene esta facultad exclusiva conforme al artículo 89, fracción X, esto es, el presidente de la República.

Dichos compromisos internacionales se encuentran condicionados para que tengan plena validez jurídica, a que observen determinadas condiciones, como son: 
1. No deberán ocuparse de la extradición de reos políticos ni de personas que hayan tenido la condición de esclavos en el país requirente ni de cualquier compromiso que altere las garantías individuales (artículo 15).

2. Se prohíbe asimismo que los estados de la Federación, "celebren alianza, tratado o coalición con otro Estado ni con las potencias extranjeras" (artículo 117, fracción I).

Esta segunda condición no impide desde luego que se combata la impunidad de los delitos cometidos fuera del territorio nacional, pues los estados de la Federación deben cooperar a obsequiar las solicitudes de extradición, pero será siempre por conducto de las autoridades federales. ${ }^{16}$

Es indudable la preocupación manifestada en el artículo 15 por respetar la dignidad de la persona, por lo que su alto contenido humanitario es digno de reconocimiento.

Existe una tercera condición que amerita un comentario especial y está contenida en el artículo 133.

Consiste en que dichos tratados sean celebrados por el presidente de la República y aprobados por el Senado, quien tiene esta facultad según el artículo 76, párrafo I.

Se ha planteado un problema derivado del uso de otros términos aparte de tratado, como son el de "convenciones diplomáticas" (artículo 76I), "alianza" y de "coaliciones" (117-I).

Como bien dice el profesor Jorge Adame Godard: "La cuestión tendría importancia si se viniera a definir dos tipos de instrumentos internacionales, unos las convenciones y convenios, que según la expresión del artículo 133 constitucional, no serían ley suprema de la Unión y otros, los tratados en estricto sentido, que sí tendrían esa categoría". ${ }^{17}$

Concluye nuestro autor concurriendo con el punto de vista del embajador Jorge Palacios Treviño, ${ }^{18}$ en el sentido de que “...todos los instrumentos internacionales de que habla la Constitución Mexicana, llámense

16 Sobre el tema ver Cruz Miramontes, Rodolfo, “Asilo y extradición. Derecho y práctica en México”, El Foro, México, Órgano de la Barra Mexicana, Colegio de Abogados, núm. 32, 1973. Asimismo, Cruz Miramontes, Rodolfo, “El caso Álvarez Machain”, Ars Iuris, México, núm. 8, Universidad Panamericana, 1993.

17 Adame Goddard, Jorge, "El Tratado de Libre Comercio en el orden jurídico mexicano", en Witker, Jorge (coord.), El Tratado de Libre Comercio de América del Norte. Análisis, diagnóstico y propuestas jurídicos, México, Instituto de Investigaciones Jurídicas, UNAM, 1993, t. I, pp. 83 y 84.

18 Palacios Treviño, Jorge, Tratados: legislación y práctica en México, México, 1986. 
tratados, convenios o convenciones, deben ser aprobados por el Senado y tienen la misma jerarquía de Ley Suprema de la Unión prevista en el artículo 133".

Siendo muy clara y precisa la conclusión anterior — que compartimos a plenitud-, nos hace cuestionar cuál es la situación de otras convenciones que pueden aparecer a la luz de las disposiciones de la Ley de Celebración de los Tratados, que fue promulgada en el Diario Oficial el 2 de enero de 1992.

Este reciente cuerpo legal, aparentemente influenciado por la práctica norteamericana, incorpora junto a los tratados, a un nuevo género de instrumentos denominados "acuerdos interinstitucionales".

Estos acuerdos serán aquellos celebrados por escrito entre cualquier dependencia u organismo descentralizado de la administración pública federal, estatal o municipal, con organismos similares extranjeros u organizaciones internacionales y que sean regidos por el derecho internacional público (artículo 2o., II).

En cuanto a las materias que podrán ser objeto de dichos instrumentos legales, se contemplan en el último párrafo del artículo citado: “El ámbito material de los acuerdos interinstitucionales deberán circunscribirse exclusivamente a las atribuciones propias de las dependencias y organismos descentralizados de los niveles mencionados que los suscriben".

Así, tenemos que tanto el presidente de la República, por disposición constitucional, como las entidades enumeradas, podrán celebrar compromisos de índole internacional, lo que nos plantea un sinnúmero de problemas e interrogantes.

Una primera cuestión es de carácter constitucional, de fondo.

Si el artículo 89, fracción X, no ha sido reformado ni tampoco el 76, fracción I, ¿de dónde emana la facultad de negociarlos?; ¿cuál es la fuente de este nuevo treaty making power?; ¿cómo explicamos la presencia ahora de estos nuevos instrumentos legales?; ¿dónde los ubicamos?

$\mathrm{Si}$ bien es cierto que tanto las autoridades municipales como los organismos descentralizados de la administración pública federal tienen capacidad legal para contratar servicios de personas, adquirir bienes de proveedores y actuar como cualquier persona moral, lo que han hecho siempre ¿estos actos adquieren el carácter internacional porque ahora se le llama "acuerdos interinstitucionales" y se rigen por el derecho internacional público? ¿Cuáles serían éstos? 
Tengamos presente que ya existen disposiciones legales cuyo campo es precisamente el mencionado, contenidas en cuerpos legales nacionales que distinguen los actos públicos nacionales de contenido privado con los propiamente públicos, o sean los que se llevan a cabo en uso de sus atributos de autoridad, y que tienen como contraparte a un país o a una persona moral extranjera.

En términos amplios, estos actos de carácter comercial excluyen, en caso de litigio, a que el demandado invoque su carácter de ente público y se cubra con el manto de la inmunidad. Sin embargo, en la práctica no es fácil deslindar cuándo un acto es privado o público o, inclusive, cuándo contiene elementos de ambas naturalezas.

Algunos gobiernos, entre los que se encuentra desde luego el norteamericano, han promulgado estas disposiciones, y bastantes dolores de cabeza nos ha producido la aplicación en nuestra contra de la Foreign Sovereign Immunities Act of 1976 (Pub. 94583-90 Stat. 2892 - T. 28 del USC, Seccs. 1330, 1332 (a) y (f) y 1602 a $1611 .{ }^{19}$

O bien de otras actividades administrativas, de cooperación, de auxilio y apoyo, educativas y otras más que el Poder Ejecutivo ha venido realizando desde hace años y que generan derechos y obligaciones inter-partes.

Como un ejemplo singular que ha llamado la atención en los foros internacionales vinculados con la administración de cuencas y ríos internacionales mencionamos a la Comisión Internacional de Límites y Aguas, en donde los problemas que surgen por el devenir caprichoso de las aguas de los ríos Tijuana, Colorado y Bravo o Grande, que constituyen frontera entre México y los Estados Unidos, se resuelven por los comisionados de ambas partes, plasmando la solución en un acta, que si no es observada en treinta días se constituye en un acuerdo internacional. ${ }^{20}$

Nos preguntamos si los autores de la ley tuvieron en mente tal vez a los denominados inter-departamental agreement que el profesor I. G. Starke describe en su manual, sin que hubieren ahondado en ellos, para codificarlos debidamente. ${ }^{21}$

19 Ver Cruz Miramontes, Rodolfo, La Ley norteamericana de Inmunidad del Estado Soberano de 1976, México, Instituto Mexicano de Comercio Exterior, 1981.

20 Ver Cruz Miramontes, Rodolfo, "Las comisiones fluviales internacionales y la Comisión Internacional de Límites y Aguas", Natural Resources Journal, University of New Mexico, t. 18, núm. 1, enero de 1978, pp. 111-129.

21 Starke, I. G., An Introduction to International Law, Gran Bretaña, Butterworths and Co., 1963, p. 323. 
La existencia de compromisos de esta índole constituye un hecho que ha estado presente en nuestra historia diplomática.

En varias ocasiones nuestros juristas se han ocupado del tema.

Recordamos entre otras las jornadas que el Instituto Matías Romero de la Secretaría de Relaciones Exteriores llevó a cabo en febrero de 1977, convocadas por el maestro César Sepulveda, su entonces director, con motivo de la conmemoración del sextuagésimo aniversario de nuestra Constitución. Dichas Jornadas se titularon "La Constitución y las Relaciones Exteriores de México", y participaron eminentes juristas, como don Antonio Martínez Báez, su tocayo don Antonio Carrillo Flores, don Felipe Tena Ramírez; el embajador Manuel Bartlett, el doctor Jorge Sayeg Helú, el doctor Jorge Carpizo y el maestro Benjamín Trillo.

Uno de los temas que más polémicas provocó fue sin duda la presencia de estos "acuerdos ejecutivos" y su ausencia de la Constitución, lo que fue calificado por algunos ponentes como una muestra de prepotencia del Ejecutivo o como una falta de atención, pero que no dejan de constituir fuentes de derechos y obligaciones. ${ }^{22}$

Más recientemente les han dedicado comentarios y reflexiones los reconocidos profesores en derecho internacional, licenciada Loretta Ortiz Ahlf y Carlos Bernal, la primera en su obra Derecho internacional públi$c o,{ }^{23}$ y el embajador Bernal en su estudio "Los convenios ejecutivos ante el derecho constitucional e internacional". ${ }^{24}$

En nuestra experiencia también, al igual que en los Estados Unidos, la pugna está presente entre los dos poderes, aunque hay diferencias notables, pues nuestras disposiciones son menos rígidas en cuanto a la votación se refiere, ya que bastarán la mitad más uno de los senadores presentes para aprobar los tratados. ${ }^{25}$

Este hecho ha dado pie a que algunos comentaristas consignen que si en la práctica norteamericana se puede explicar la existencia de los acuerdos ejecutivos como una forma de evadir enfrentarse al Senado y arrancarles 66 votos (dos terceras partes). En México no es admisible esta explicación.

22 Secretaría de Relaciones Exteriores, Los convenios ejecutivos ante el derecho constitucional e internacional, México, Instituto Mexicano "Matías Romero" de Estudios Diplomáticos, s.f.

23 Ortiz Ahlf, Loretta, Derecho internacional público, México, Harla, 1993, pp. 45-57.

24 Bernal, Carlos, "Los convenios ejecutivos ante el derecho constitucional e internacional", Jurídica, México, Universidad Iberoamericana, núm. 12, 1980.

25 Artículos 63 de la Constitución y 158 del Reglamento para el Gobierno Interior del Congreso General de los Estados Unidos Mexicanos. 
$\mathrm{Si}$ añadimos que tradicionalmente se contaba con un cuerpo senatorial de control mayoritario por el mismo partido político del Ejecutivo, resultaba menos entendible la práctica de estos acuerdos simplificados.

El tema no es nuevo de ninguna manera, pues ya desde 1856 fue abordado en los debates del Constituyente, y ahí Francisco Zarco enérgicamente condenaba la práctica viciosa del Ejecutivo, pues: “...Con el nombre de Convenciones los gobiernos constitucionales han celebrado pactos que son verdaderos tratados... disponiendo de sus rentas e imponiéndoles compromisos. Y estos pactos se han escapado de la revisión del Congreso de una manera abusiva, y sólo porque la Constitución no empleaba la palabra Convenciones". ${ }^{26}$

Como se desprende, no se trata solamente de un juego de palabras, sino de algo mucho más importante y delicado.

Tan presentes han estado que el H. Senado de la República, en su magnífica obra Tratados ratificados y convenios ejecutivos celebrados por México, dice lo siguiente:

3. Además de los Tratados que constituyen Ley Suprema, se incluyen igualmente los que se conocen como acuerdos o convenios ejecutivos o como acuerdos o tratados ejecutivos y que son los que celebra México por conducto del titular del Poder Ejecutivo Federal pero que no se someten a la aprobación del H. Senado.

Estos Tratados si bien no forman parte de la Ley Suprema de la Unión... sí constituyen Ley Ordinaria... ${ }^{27}$

La Ley sobre la Celebración de Tratados en comento apareció al inicio de 1992, y coincide con los albores de las negociaciones del entonces futuro Tratado de Libre Comercio Mexico-Estados Unidos.

Este hecho puede hacernos presumir que ante la eventualidad de alcanzar la meta deseada y culminar exitosamente las negociaciones, que a la sazón se vislumbraban solamente bilaterales, resultaba útil prevenir los mecanismos que facilitaron la implementación y la actualización de sus disposiciones que a lo largo del periodo que se acordara serían necesarios.

26 Zarco, Francisco, Historia del Congreso Extraordinario Constituyente (1856-1857), según cita del maestro don Antonio Martínez Báez, "Ponencia del doctor Antonio Martínez Báez", en Secretaría de Relaciones Exteriores, Los convenios ejecutivos ante el derecho constitucional e internacional, México, Instituto Mexicano "Matías Romero" de Estudios Diplomáticos, s.f., p. 16.

27 Senado de la República, Tratados ratificados y convenios ejecutivos celebrados por México, México, 1972, t. I, p. XIII. 
No podemos consignar con certeza si se tenía una idea del periodo de vida del Tratado, pero suponemos con seguridad que estimaron no sería corto.

De ahí nuestra suposición de que esta ley fue vista hacia el futuro más que como resultado de una experiencia histórica que clamaba por una regulación.

La pertinencia de la tarea ordenadora era evidente si tomamos en consideración, conforme los datos aportados por el embajador Carlos Bernal en su estudio citado, ${ }^{28}$ que: "De un total aproximado de 1,040 instrumentos internacionales celebrados por México entre los años de 1821 a 1972, tan sólo alrededor del 66\% de ellos fueron aprobados por el Senado o por el Congreso cuando las Constituciones establecían el sistema bicameral".

Si bien esta Ley se inserta en la nueva política internacional aperturista que nuestro país inició desde la década de los setenta y que vino a confirmarse en las acciones de 1989 a $1994^{29}$ tendientes a la preservación y fortalecimiento de la soberanía, la protección de los derechos e intereses de los mexicanos en el exterior y la cooperación internacional, tal como reza la exposición de motivos de la misma, no entendemos por qué no se tomaron en cuenta los antecedentes históricos, la experiencia diplomática y sobre todo los mandamientos constitucionales, reformándose en lo que fuera menester para cumplir exitosamente con los objetivos pretendidos.

Sería absurdo suponer por otra parte que si los acuerdos interinstitucionales no son ley suprema de la nación como expresamente se reconoce en el párrafo siete de la citada exposición de motivos, quedan sin sustento ni base jurídica.

Al establecer y crear obligaciones y derechos a las entidades celebrantes se asemejan al Poder Legislativo, y al ocuparse de un sinnúmero de temas atentan contra el artículo 73 en las fracciones que invaden, así como en las propias a las cámaras legislativas.

Más aún: se afrenta al artículo 117 constitucional, pues se faculta a las dependencias y organismos descentralizados estatales y aun municipales, a llevar a cabo los actos prohibidos expresamente a los estados de la Federación. 
Al revisar, al azar, algunos párrafos del precepto citado, como el III, el IV, el VIII y los demás que atan a los poderes estatales, tenemos que ahora podrán hacer lo que se les ocurra vía sus dependencias inferiores.

El espíritu y la letra del artículo 117 son muy claros. El maestro Enrique Sánchez Bringas nos lo recuerda con meridiana claridad:

Así pues las facultades prohibidas a los estados pueden clasificarse en absolutas y relativas; las primeras se contienen en el artículo 117 y se les identifica como absolutas porque en ningun caso y por ningún motivo pueden realizarlas...

De esta manera resulta incontestable que el artículo 117 Constitucional, encuentra su justificación existencial en la necesidad de mantener el pacto federal por medio de la clara determinación de competencias entre la Federación y las entidades federativas. ${ }^{30}$

Ahora resulta, consideramos a la luz de lo dicho, que todo esto queda marginado mediante la elusión que esta ley comentada establece y permite.

$\mathrm{Su}$ promulgación no fue afortunada, y parece generada por premuras $\mathrm{y}$ adecuaciones a situaciones coyunturales.

La calificación de inconstitucional es evidente, y nos unimos a las opiniones de los maestros citados que con mayor precisión y fortuna han analizado el hecho. ${ }^{31}$

En contraste con esta invitación que hace la ley en comento para que nazcan un sinfín de compromisos internacionales, la Suprema Corte de Justicia, en Pleno, acaba de fortalecer a los tratados internacionales de una manera definitiva al establecer que tendrán una jerarquía superior a las leyes federales, con la cual modifica el criterio que venía sustentando en el pasado, que los consideraba de igual condición, siguiendo la letra del artículo 133 constitucional. ${ }^{32}$

Afortunadamente los acuerdos interinstitucionales, por definición propia, no se equiparan a los tratados y no son ley suprema de la nación (exposición de motivos, párrafo 7).

30 Véase Sánchez Bringas, Enrique, “Artículo 117”, Constitución Política de los Estados Unidos Mexicanos comentada, México, Instituto de Investigaciones Jurídicas, UNAM, 1985, pp. 286 y 287.

31 Carlos Bernal califica a los acuerdos ejecutivos no aprobados por el Senado como inconstitucionales, op. cit., nota 24, p. 56. Ortiz Ahlf, Loretta, op. cit., nota 23, p. 52.

32 Tesis, p. LXXVII/99, p. 46, tomo X, noviembre de 1999. 
El análisis que realizamos nos lleva necesariamente a mencionar, con la brevedad del caso, pero con el espacio necesario, una de las explicaciones contenidas en la citada exposición de motivos, para su existencia.

Dicha razón estriba en la pertinencia de actualizar el sistema de la negociación de los compromisos internacionales y "...precisar la obligación de coordinar las acciones de las dependencias y organismos descentralizados de la Administración Pública Federal, con la Secretaría de Relaciones Internacionales en la celebración tanto de tratados internacionales como de acuerdos interinstitucionales".

Para ello se han considerado las convenciones de Viena sobre el Derecho de los Tratados y la que se aplica a los Tratados entre Estados y Organismos Internacionales, la primera de 1969 y la segunda de 1986, ratificadas por nuestro país en 1974 y en 1988, respectivamente.

Dada la necesaria referencia que haremos más adelante al valorar los efectos jurídicos de las "cartas paralelas" de la Convención de Viena, nos referiremos brevemente a los elementos más destacados de la misma.

\section{LA CONVENCIÓN DE VIENA SOBRE EL DERECHO DE LOS TRATADOS DE $1969^{33}$}

La Asamblea General de las Naciones Unidas adoptó el 23 de mayo de 1969 el proyecto elaborado durante varios años por la Comisión de Derecho Internacional de esa organización, y entró en vigor al completarse la trigésima quinta ratificación, el 30 de enero de 1980. "Consecuentemente — como acertadamente sostiene el maestro César Sepúlvedacoexisten dos regímenes jurídicos diversos sobre los tratados internacionales. Uno de ellos es el que se contiene en esta Convención de 1969... El otro es el establecido por el derecho consuetudinario...". ${ }^{34}$

Esto es, que para nuestro país, que ha suscrito el Tratado, se aplican sus disposiciones, y en lo no comprendido se estará al segundo, que cubre la gran mayoría de países.

En cambio, para los Estados Unidos de América, que no ha ratificado el Tratado, no se acoge a las disposiciones de la Convención de Viena. El ámbito de aplicación de la Convención es el tratado que celebren dos o más Estados (artículo 1o.).

34 Sepúlveda, César, Derecho internacional público, 18a. ed., México, Porrúa, 1997, p. 562. 
¿Qué se entiende por "tratado"? "Un acuerdo internacional celebrado por escrito entre Estados y regido por el derecho internacional... cualquiera que sea su denominación particular" (artículo 2o., párrafo I a) (énfasis añadido).

Entresacaré enseguida los preceptos que pueden ser más cercanos a nuestro tema y a los que recurriremos más adelante.

El artículo 7o. parte del supuesto de que todo Estado tiene la capacidad para celebrar tratados, y que no se requiere necesariamente los plenos poderes de los funcionarios para obligar al Estado, pues puede asumirse que los tiene si por la práctica así se infiere, o bien, en virtud de sus funciones representan al Estado.

El consentimiento puede expresarse de muchas formas, como por ejemplo la firma, el canje de instrumentos, la ratificación, la adhesión y otros más (artículos 11 al 17).

En cuanto al cambio del texto del tratado, se distinguen dos maneras: la enmienda y la modificación.

La enmienda es la alteración formal de ciertas disposiciones que afecta a todas las partes del tratado (artículo 40).

La modificación es cuando sólo afecta a la relación entre algunas partes del Tratado, pero no a todas (artículo 41).

En ambos casos se prevén algunas normas de procedimiento, pero siempre estará presente la obligación de notificar a las demás partes del Acuerdo (artículos 40, p. 2 y 41, p. 2).

Existen desde luego muchos puntos más de importancia e interés, pero por ahora sólo deseamos llamar la atención de aquellos que pudieran aplicarse a nuestra valoración legal.

En síntesis, podemos considerar que de lo dicho hasta ahora:

1) Tenemos ya un panorama adecuado de lo que es el TLCAN, como marco general de los compromisos contraídos por las partes.

2) Conocemos cómo quedaron concertados los derechos y las obligaciones bilaterales de México y los Estados Unidos en el tema del azúcar y edulcorantes.

3) Sabemos también de la existencia de las cartas paralelas sobre estos productos agrícolas, que fueron elaboradas a última hora, suscritas solamente por los secretarios de Comercio.

4) Conocemos sus textos, que siendo casi iguales presentan ciertos matices que las afectan en sus consecuencias. 
5) Estamos informados de cómo se presentaron al Congreso norteamericano, en un paquete distinto al que contenía el texto del TLC.

6) Explicamos cómo en los Estados Unidos se estilan los llamados "acuerdos ejecutivos", sus distintos tipos y sus efectos legales.

7) Asimismo, cuál es la situación en México de la práctica y del intento de su reglamentación legal.

8) Por último, sabemos de la existencia de un tratado multilateral que se aplica para regular la celebración de tratados, conocida como la Convención de Viena, y de la ausencia de los Estados Unidos de ella.

Toca ahora en esta última parte ocuparnos específicamente de analizar las "cartas paralelas" de otros documentos relacionados y de su apreciación legal.

Advertimos que esta situación, por ser anómala, aunque no extraordinaria, lamentablemente, constituye una práctica viciada que atenta contra la seguridad y certeza que se pretende lograr con la suscripción de los tratados internacionales y con su publicidad a través de su inscripción en los organismos internacionales, trátese del más general, como es la Organización de las Naciones Unidas, o especial, como la Organización Mundial de Comercio.

Por lo tanto, al ser ahora objeto posiblemente de un panel de expertos que las analice, pondere y opine, nos permite a nuestra vez hacer lo propio como estudiosos de estos temas jurídico-internacionales.

Por ende, es intrascendente si se instala y opera el grupo especial en cuestión, o bien se acuerda por los afectados dejar las cosas por la paz.

El problema está sobre la mesa y llama a que se le analice, conozca y se juzgue.

\section{ESTUDIO ANALÍTICO \\ Y OPINIÓN SOBRE LAS “CARTAS PARALELAS”}

De entrada recordaré que la presentación de dichos documentos en forma oficial al Congreso norteamericano el 4 de noviembre de 1993 forma parte de un paquete que contiene otros documentos, y que dichas cartas enlistadas bajo el numeral " 2 " contienen otras englobadas bajo el título de "cítricos". 
Por lo tanto, solamente nos ocuparemos de las susodichas, que se refieren al azúcar y a los edulcorantes.

Asimismo, tengamos presente que con anterioridad a esta presentación, pero el mismo día, se le había enviado al Congreso el paquete obligatorio conforme al fast track, del texto del TLCAN y de los instrumentos legales para su implementación.

Como sabemos, de manera expresa el presidente Clinton advierte que fuera de los documentos anteriores contenidos en el paquete 1 (como lo denominaremos por comodidad para su identificación), los demás no tienen que ser aprobados por el Congreso, y que solamente se los entrega en el paquete 2 para su conocimiento, que permita sensibilizarlos dados los beneficios que pueden darle a los Estados Unidos, pero sólo sucederá si aprueba el TLCAN. Los congresistas se ocuparon de revisar, eventualmente leer y en algunas ocasiones concretas, opinar.

Existe un documento intitulado "Record Debate in U.S. Congress on Constitutionality of Side Agreements of the North American Free Trade Agreement" de más de 600 páginas, en donde constan los comentarios, juicios y opiniones de senadores y diputados.

Hay varias presentaciones que serán útiles en el abordaje que hagamos a continuación del caso.

Por razón de orden empezaremos por referirnos a la situación de las cartas paralelas en México, luego su consideración legal en los Estados Unidos, y concluiré con una visión general a la luz del tratado en sí y del derecho internacional.

\section{Situación en México}

No hemos comentado hasta ahora qué destino se le dio a estas "cartas paralelas", en los ejemplares que necesariamente debió tener en su poder, pues siendo cruzadas lo entendible sería que los originales fueran al gobierno socio y se conservara una copia de la propia.

En su oportunidad hubo declaraciones y comentarios breves de las autoridades informando a la opinión pública de la existencia de unas cartas calificadas como de "técnicas", que servirían para precisar algunos puntos del TLCAN que así lo requerían, para facilitar su aplicación sin complicaciones. ${ }^{35}$ 
Posteriormente, en declaraciones a los medios de comunicación, el titular de la SECOFI informó en una comparecencia ante el H. Senado de la República y a varios reporteros que indagaron sobre las "cartas paralelas" que no se habían presentado con el texto del tratado, por ser innesario, ya que solamente eran documentos técnicos de apoyo al mismo. ${ }^{36}$

Esta situación fue ratificada recientemente en la reunión de la Cámara de Senadores que integra la LVIII Legislatura federal celebrada el 10 de octubre de 2000, afirmando en el punto de acuerdo núm. 1: "Que los documentos Cartas Paralelas no fueran sometidas a la consideración o aprobación del Senado de la República, y por lo tanto no cumplen con lo dispuesto en el artículo 133 de la Constitución Política de los Estados Unidos Mexicanos". ${ }^{37}$

A mayor abundamiento, y dado que es un principio general del derecho internacional público que no se pueden desconocer compromisos internacionales alegando deficiencias de derecho interno, será pertinente formular otras consideraciones.

1a. Dado que las "cartas paralelas" no fueron negociadas por el presidente de la República ya que sólo aparece el nombre del doctor Jaime Serra Puche, secretario de Comercio y Fomento Industrial en la antefirma y no fue conocida por el H. Senado de la República, no constituye un tratado internacional en los términos constitucionales ya citados frecuentemente.

2a. Para estimarse como un "acuerdo intersecretarial" elaborado entre la USTR y la SECOFI deberían haberse seguido los lineamientos que el artículo 7o. de la llamada Ley de Tratados previene.

Haciendo caso omiso de nuestra opinión sobre la inconstitucionalidad de la misma y suponiendo — sin conceder - que no lo sea, la SECOFI debió haber informado a la Secretaría de Relaciones Exteriores, de su pretensión para celebrar tales convenios. Posteriormente haber obtenido un "dictamen", como se le califica, de dicha dependencia.

Si fuera favorable debió haberlo inscrito en el registro respectivo.

En una indagación que realicemos ante la Secretaría de Relaciones Exteriores fuimos informados de que desconocían la existencia de tales

36 Gazcón, Felipe, Reforma, México, 3 de septiembre de 1997, sección de Negocios; González, Lourdes, El Financiero, México, sección Economía, misma fecha; Mena, Yadira, El Economista, México, sección Industria y Comercio, misma fecha.

37 Véase la Propuesta que en defensa de la Industria Mexicana del Azúcar tomará el H. Senado de la República considerando que es de urgente resolución. También Rodríguez, Leticia, "El Senado presiona a Zedillo sobre el caso del azúcar”, El Financiero, México, 11 de octubre del 2000. 
cartas, pues nunca habían producido dictamen alguno, y menos inscrito los susudichos documentos.

Por lo dicho, esta segunda argumentación nos acredita que tampoco tienen el carácter de "acuerdos interinstitucionales", por lo cual son inexistentes conforme a esta ley.

3a. No faltará quien pretenda superar estas presentaciones y alegue que conforme a la Convención deViena México está obligado a respetarlas, pues el artículo 2o., párrafos 1, a) y 2, de este instrumento así lo consignan.

Primeramente debemos precisar si la sola firma — si estuviera estampada, del secretario de Comercio y Fomento Industrial- puede considerarse como el representante del Estado, con facultades suficientes para obligarlo, tal como ya consignamos que lo establecen los artículos pertinentes de la Convención.

No es fácilmente aceptable cuando el tratado que pretenden modificar fue firmado por el presidente de la República y no por el secretario, conforme sucedería en la hipótesis planteada en el artículo 7o., párrafo b), cuando supone que se puede deducir de la práctica seguida por el Estado en cuestión que la persona que aparece en el documento, o sea el titular de la SECOFI, ha sido considerada representante del Estado para esos efectos.

Menos aún se aceptaría en los supuestos que aparecen en el párrafo 2 del mismo precepto, ya que se parte de las funciones que realiza, y siempre que se trate de:

a) Jefes de Estado.

b) Jefes de misiones diplomáticas.

c) Representantes acreditados por los Estados ante una conferencia internacional o ante una organización internacional.

No obstante la falta de realización de las hipótesis anteriores, existe en el artículo 8o. una prevención que permite "purgar" la deficiencia legal que se pudiera presentar, y esto se da si el Estado a quien se pretendió representar sin razón confirma a posteriori el acto llevado a cabo.

En el caso a consideración ya hicimos referencia que el Senado mexicano acaba de ocuparse del tema al rechazar las "cartas paralelas" por no haberlas conocido en su oportunidad, confirmando así su invalidez jurídica. Por ende, tampoco se actualiza esta posibilidad. 
En cuarto término, reparemos en el propósito y efectos buscados por las "cartas", consistente en modificar el texto del anexo 703.2 en su párrafo 15, y eliminar el párrafo 16.

En otras palabras, se buscaba enmendar y modificar el tratado.

Ya hicimos referencia a que la parte IV de la Convención de Viena se ocupa precisamente de estos puntos, y que los artículos 39, 40 y 41 restablecen las normas procedimentales que se deben observar para estos efectos.

Una primera condición es que se respete lo que el propio tratado disponga sobre el particular.

Ergo, debe existir válidamente el tratado, por lo que en la especie aún no había sido aprobado ni por el Congreso norteamericano ni tampoco por los cuerpos legislativos de México y Canadá.

Así pues, aún no había tratado que enmendar. Lo lógico hubiera sido que las partes hubiesen abierto el texto y renegociado.

No sucedió así, y la razón simple fue que ya no tenía facultades el Ejecutivo norteamericano para negociar, como lo comentamos líneas arriba.

Por lo tanto, reiteramos nuestra observación de que no es posible aplicar tampoco este supuesto sobre la modificación y enmienda del aún inexistente tratado.

En lo que corresponde a nuestra ley interna, y considerando que los tratados devienen ley suprema, su modificación debe hacerse conforme al artículo 72, párrafo f), que dice: “En la interpretación, reformas o derogación de las leyes o decretos, se observarán los mismos trámites establecidos para su formación".

Al no haberse cumplido, carecen de efectos legales.

Para concluir esta última parte de nuestro estudio recordaremos que la Convención de Viena aún no está aceptada por el gobierno norteamericano por lo que sus disposiciones no le son aplicables al caso en estudio, y estimamos que difícilmente la llegará a firmar.

El profesor John H. Jackson, ya mencionado, opina sobre la Convención que es: “...a convenient reference on the rules of international law, or those governing treaties, even though various nations are not bound (not formal parties, such as the United States)...".38

Decidimos, sin embargo, efectuar el análisis para despejar cualquier duda, pues no ha faltado quien insista en el compromiso de México, sin 
reparar en la inaplicabilidad legal del Acuerdo. De cualquier forma resulta útil, ya que se han recogido en las normas del mismo las corrientes y las prácticas aceptadas por los Estados como válidas.

\section{Situación en los Estados Unidos de América}

Habiendo ya considerado el tema de la existencia de los acuerdos ejecutivos y de los diversos tipos que en la práctica diplomática norteamericana existen, procederemos a referirnos a la ubicación de las "cartas paralelas" en el sistema.

De inicio tenemos que el TLCAN es un acuerdo ejecutivo-congresional, y que a su alrededor, cual satélites, giran tres acuerdos suplementarios y las "cartas paralelas" y otros documentos adicionales cuya condición jurídica es distinta.

La revisión de los mismos nos señala de inmediato que son perfectamente ubicables en diversos cajones de clasificación legal, acorde tanto con textos previos existentes en normas positivas y en las decisiones e interpretaciones que la Suprema Corte ha dado, sobre todo por la afectación que pueden dar a leyes federales y locales, así como a la soberanía de los estados de la Unión.

Así es aceptado que el gobierno norteamericano puede obligarse internacionalmente, no sólo por la vía de los tratados senatoriales, sino también por la de los acuerdos ejecutivos (United States vs. Curtis Wright Export Co, 299US304 (1936)).

Lo que nos interesa ahora es precisar hasta dónde pueden ser válidos los compromisos adquiridos en materia comercial, sin que sean aprobados por el Senado.

La razón es que dada la competencia original del Congreso sobre esta materia, su manejo por el Ejecutivo se antoja que no puede ser informal ni simple. El ejemplo del TLCAN es muy claro, ya que previamente a su negociación hubo que recabar una autorización expresa del Congreso, quien no solamente la otorgó, sino que la sujetó a un término perentorio para su negociación y le fijó ciertas condiciones.

Habiendo sido negociado en tiempo y forma, el TLCAN tiene así el estatuto de un acuerdo ejecutivo congresional.

Sus características coinciden con las apreciaciones formuladas en un caso clásico en la materia, como es Weinberger vs. Rossi 456 U.S. 25 (1982), 
o bien B. Altman and Co. vs. United States 224 U.S. U.S.583,601 (1912), así como Dames and Moore vs. Regan 453 U.S. 654,686 (1981).

Empero, no se puede desconocer que hay voces, sobre todo en los medios académicos, que se han alzado en los últimos años en contra de esta práctica del Poder Ejecutivo y que han llegado a cuestionar la constitucionalidad de tratados tan importantes como el que se refiere a la suscripción de la Organización Mundial de Comercio.

En el seno del Congreso y en diversas ocasiones se han efectuado reuniones de estudio sobre el tema, como sucedió en 1975 y en 1976, en que han dado pie a la revisión del pensamiento de especialistas en el tema como Rovine, Mathews, McDoughal and Laws, Borchard, Lung Chun Yen, Geshard von Glahn, Joseph M. Sweeney y otros. ${ }^{39}$

El resultado ha quedado plasmado en la regulación jurídica que ha producido en las leyes ya mencionadas de 1974 y 1988.

Sin embargo, en donde no hay esta claridad legal es en el caso de los demás tipos de acuerdos ejecutivos que son los acuerdos ejecutivos presidenciales o sole executive agreements.

\section{A. Los acuerdos ejecutivos presidenciales y las cartas "paralelas" conforme al derecho y a la práctica norteamericanos}

Hemos advertido con anterioridad en la parte conducente que en contraste con los acuerdos ejecutivos congresionales, los llamados "presidential" o "sole" executive agreements presentan serias dudas de su legitimidad frente a la Constitución norteamericana.

En su origen se consideró que el presidente norteamericano tenía ciertas facultades implícitas para el mejor desempeño de su encargo, que podía manejar con cierto arbitrio, sin intervención alguna del Senado (artículo II, sección 2, párrafo 1).

Ocasionalmente inclusive se citó la tesis doctrinal del ejercicio ultra vires del poder presidencial y su admisión como vinculante en el derecho internacional. ${ }^{40}$

Durante varios años y en ocasiones diversas se han utilizado estos instrumentos fundamentalmente en materia de conflictos bélicos o de

39 Dejo constancia de mi reconocimiento agradecido al colega Irwin P. Altschuler y socios, por su apoyo, información bibliográfica y valiosos comentarios sobre el particular.

40 Cuestionamiento formulado por el senador Brewster al asesor legal del Departamento de Estado, G. H. Hackworth, en el asunto de la vía acuática del San Lorenzo, el 29 de noviembre de 1944, citado por William W. Bishop, International Law, Nueva York, Prentice-Hall, 1954, pp. 90 y 91. 
confrontaciones complicadas, en donde ha prevalecido un gran interés político. El Departamento de Estado editó en 1950 una obra en la que se revisa esta práctica diplomática y se destaca lo anterior. ${ }^{41}$

Directamente conectados con estos mecanismos existen dos casos muy imporantes en la historia del incremento territorial de los Estados Unidos, uno de los cuales infortunadamente afectó a México.

Durante varios años, casi diez, Texas tuvo una existencia independiente para anexarse posteriormente a quien estuvo sosteniendo la guerra contra su sede.

El 12 de abril de 1844 se firmó el tratado de anexión con la República de Texas, pero al presentarse ante el Senado norteamericano fue rechazado por razones diversas, la más importante de ellas pretendía que tuviera una mayor formalidad.

La respuesta no desanimó al señor Calhoun, secretario de Estado, pues vía resoluciones conjuntas de cada una de las Cámaras, cuyos integrantes votaron por mayoría simple, se obtuvo la conformidad buscada por el Ejecutivo, eludiéndose así la intervención del Senado, conforme lo previene la Constitución, ${ }^{42}$ la cual se pronunció el 1o. de marzo de 1845 , decidiendo la creación de un nuevo estado, y el 29 de diciembre del mismo año se consumó la anexión.

En forma parecida se efectuó la anexión de Hawai el 7 de julio de 1898.43

En ambos casos quedó de manifiesto que la utilización de los sole executive agreements pese a los enormes beneficios económicos y políticos norteamericanos que producirían, requerían de una mayor formalidad, y en cierta forma se manifestó pudor. Tal como se dijo en otra ocasión, requerían de cierta "dignidad".

No ha faltado desde luego oportunidad de que la Suprema Corte de Justicia se pronuncie a favor de estos acuerdos o actos "grises", confor-

41 The Law of Treaties as Applied by the Government of the United States of America, ver también The restaement (third) of foreign relations law.

42 La bibliografía sobre el episodio texano es abundante, por lo que sólo citaré algunas obras relevantes sobre este punto, como la de Smith, Justin H., The Annexation of Texas, Nueva York, A. M. Press, que originalmente fue publicada en 1911, se reimprimió en 1971. Asimismo, Republic of Texas. Its History and Annexation 1836 to 1846, escrita por quien fuera su último presidente Anson Jones. Edición facsimilar por The Rio Grande Press, Chicago, 1966. Asimismo, ver "Texas vs. White" 74 U.S. (7 Wall, 700 (1868)).

43 Bishop, William B., op. cit., nota 40, p. 87. "Hawai vs. Mankechi” 190 U.S. 197 (1903). 
me al criterio de que los postulados y requerimientos de la globalización demandan un ejercicio fuerte de los poderes presidenciales.

Se citan obligatoriamente los casos de United States vs. Belmont 301 U.S., 324 (1937), United States vs. Pink 315 U.S.203, 229-30 (1942) у Dames and Moore vs. Regan 453 U.S. 654 (1981).

Este tercer juicio se ha convertido en una especie de clásico, pues no sólo confirma la tesis de la facultad legítima presidencial para actuar de manera independiente respecto del Senado y comprometer internacionalmente a su país, sino además para obligar directamente a los mismos estados de la Unión, y fortalecer sus acciones en otro terreno, como es el de las reclamaciones internacionales en contra de los Estados Unidos.

La materia del caso fue la retención como rehenes y su liberación por el gobierno de Irán, a cambio de resolver las demandas pendientes ante tribunales norteamericanos en contra de este país, lo que afectó también en cierta manera las funciones jurisdiccionales.

Algunos analistas han considerado que el Congreso implícitamente ha favorecido esta práctica de resolución de quejas y reclamaciones por la vía de los sole executive agreements, lo que se demuestra con la promulgación de la International Claims Settlement Act, 22 U.S.C., sección 1623 (a), 1988.

Empero, no han faltado comentarios de algunos analistas en el sentido de que dada la circunstancia de que varios casos de reclamaciones han requerido de ciertas leyes de implementación o de aprobación posterior, no constituyen sole executive agreements en esencia.

La crítica ha sido constante y se ha incrementado en contra de estos acuerdos, por carecer de validez constitucional.

Por ello, el profesor Steve Charnovitz considera que se está presentando un resurgimiento de la posición defendida por el congresista Brieker, y que su propuesta modificatoria que lleva su nombre pronto volverá a la luz, buscando poner coto y límites a estas acciones presidenciales ausentes de apoyo constitucional. ${ }^{44}$

Tanto el profesor citado líneas arriba como otros autores, entre ellos, Sandra Le Priol-Vrejan, ${ }^{45}$ se han ocupado de los acuerdos suplementarios

44 Charnovitz, Steve, "The NAFTA Enviromental Side Agreements", International and Comparative Law Journal, 1994, pp. 257, 295-97.

45 Priol-Vrejan, Sandra Le, "The NAFTA Enviromental Side Agreement and the Power to investigate violations of Enviromental Laws", Hobstra Law Review, núm. 23. 
del TLCAN, o sean el laboral y particularmente del que se refiere a la protección del medio ambiente, y han criticado y puesto en duda su legitimidad.

Con todo esto, podemos concluir que existen serios cuestionamientos internos sobre la legitimidad y validez de las "cartas paralelas", y con ello de que puedan exigirse a México en los términos pretendidos, ya que su ubicación y encuadramiento dentro del sistema de acuerdos internacionales del Ejecutivo sólo pueden calificarse de sole executive agreements.

Quien dude que lo son que recuerde que el presidente Clinton tuvo el buen cuidado de precisar en la carta que acompañó al paquete 2 de documentos enviados al Congreso el 4 de noviembre de 1993, que había acuerdos suplementarios y otros documentos, entre los cuales enlista a las cartas sobre azúcares y edulcorantes.

Esta distinción, como advertí al inicio de este artículo, no es fortuita, pues hace un distingo de la diferencia legal entre ambos acuerdos, si bien los primeros constituyen acuerdos ejecutivos presidenciales, los segundos fueron menos informarles, y se anunciaron desde la autorización del fasttrack en mayo de 1991, cuya celebración siguió a la firma del TLCAN, y se concluyeran el 13 de agosto de 1993, según lo informaron públicamente los tres gobiernos asociados. A los demás sólo los califica de acuerdos y otros documentos.

No dejó de llamar la atención de los congresistas que habiéndose concluido el TLC, considerado como un acuerdo fuera de la aprobación del Senado, pero al fin de cuentas autorizado y en vías de aprobación por el Congreso, conforme a la "vía rápida", aparecieran ahora estos convenios suplementarios.

Un grupo de legisladores en número de once cuestionaron al presidente Clinton sobre la condición legal de los convenios y así, a través de una carta del diputado George Brown se lo hicieron saber el 20 de julio de 1993. El representante para el Comercio Internacional, Mickey Kantor, tardó en responder, y el 8 de octubre les hizo saber que se trataba de unos acuerdos ejecutivos presidenciales (sole), y textualmente dijo: "The supplemental agreements are executive agreements. The agreements do not require Congressional Approval since they are executives agreements and are not formally part of or annexed to, the NAFTA."

La corriente de opinión prevaleciente en el Congreso fue en el sentido de que los acuerdos suplementarios eran sole executive agreements, 
según comentó el senador por Rhode Island, John H. Chafee, quien de manera contundente afirmó entre otras cosas que:

The President can enter into the side agreements without approval of Congress, because they are not trade agreements...

The side agreements are not before us. If you look at this legislation the side agreements are not in it...

Charnovitz se refiere a esta opinión y a otras para juzgar la ilegitimidad de los acuerdos laterales.

Si estimamos que las cartas paralelas aun se ubican en un nivel inferior a los acuerdos laterales, que sí habían sido mencionados por el Congreso y previamente el presidente había dado cuenta de su conclusión desde agosto, y se duda de la validez legal de ellos, con mayor razón las citadas cartas menos presencia tienen.

\section{B. ¿El presidente Clinton pudo celebrar los acuerdos laterales y las cartas paralelas?}

La pregunta que nos hacemos surge de la existencia de una facultad arbitral e indeterminada, un tanto existente en la penumbra de las atribuciones inherentes a su ejercicio, que han defendido funcionarios del Ejecutivo y pretendido justificar algunos legisladores.

En principio pudiera parecer por lo dicho que sí puede, en razón de que son acuerdos ejecutivos, y la práctica lo apoya.

Tenemos que estimar en justicia que no están encerrados ambos en un mismo cajón; por lo tanto, si los primeros pudiesen explicarse, los segundos no.

De cualquier manera, su oportunidad es criticada, y por ello su validez legal, pues todos ellos, como ya consignamos, forman parte de un todo, y para que operen y funcionen debe primeramente ser aprobado el TLCAN como lo dijo claramente el presidente Clinton en su carta que acompañó al paquete 2. Por ello no es posible legalmente separarlos del principal.

Recordando, el Ejecutivo tenía una autorización para negociar y concluir el TLC en un plazo concreto que expiró el 31 de mayo de 1993.

Tanto los acuerdos suplementarios como las cartas paralelas se firmaron con posterioridad, por lo que no era ya legalmente posible hacerlo, $y$ 
admitirlos significa aceptar un ejercicio fuera de las facultades presidenciales; esto es, hubo un exceso de autoridad.

Así pues, todos estos documentos están viciados de nulidad.

Citaremos por su pertinencia lo que manifestó el senador Stevens, de Alaska, a propósito, tomado del extracto del documento citado. ${ }^{46}$

The NAFTA side agreements overstep the authority of the President, because:

Additional nontrade side agreements under fast-track are unprecedented and were not authorized or mentioned in the fast-track legislation passed by Congress.

Side agreements wer negotiated more than two months after the expiration of presidential fast track authority on June 1, 1993.

Because they are nontrade in their subject matter, the side agreements cannot be considered "necessary and appropriate" under the language of the Trade Act of 1974, and, thus, the Administration's stated reason for including the side agreements with the NAFTA implementing legislation is negated.

The President did not meet his obligation under the Constitution, which grants Congress the authority to regulate foreing commerce, to consult and gain the pproval of Congress before entering into international agreements. The side agreements are, thus, without legal effect.

La contundencia de la opinión es evidente y precisa, por lo que su conclusión abona nuestra opinión.

En suma, siendo la facultad presidencial en cuestión no muy precisa, pero en fin, ejercida en ciertas materias, en el presente caso no es admisible tampoco porque lo hizo fuera del tiempo contemplado por el Congreso para ello.

Esto explica con razón que el presidente hubiera enviado en un paquete distinto, el número 2 , los acuerdos suplementarios y "otros documentos" y además advirtiese que no tenía obligación de hacerlo, pues el fast-track no lo preveía ni tampoco el Congreso debía aprobarlos.

De aquí la insistencia del mandatario para pretender separarlos del TLC, en un esfuerzo por hacerlos aparecer como una cosa distinta.

El Congreso no cayó en el juego, y los ha visto lógicamente como partes de un todo.

46 Record of debate in U.S. Congress on Constitutionality of Side Agreements of The North American Free Trade Agreement (vol. 139, núm. 162), 139 Cong. Rec. S. 16352. 


\section{Tampoco debieron haberse celebrado las cartas paralelas pues su propósito es ilegítimo y carecen de apoyo legal}

Es claro por el texto de las "cartas paralelas" que pretenden modificar el texto del TLC en los párrafos 15 y 16 del anexo 703.2, ya que cambian lo negociado en el primero y desaparecen al segundo. ${ }^{47}$

La razón es indudable: proteger aún más a la industria azucarera norteamericana.

Ya explicamos los antecedentes, y a ellos nos remitimos. El efecto de las susodichas cartas dejarán a la industria mexicana sin la posibilidad de exportar al mercado norteamericano en cuota todos sus excedentes más allá de un supuesto tope.

Además, al irse incrementando la demanda interna de fructosa el excedente será cada vez menor.

Dichas cartas ni aun consideradas aisladamente pueden tener valor legal, pues al cambiar el texto del TLCAN, aprobado por el Congreso, requeriría su aprobación para modificarlo.

En otros casos se ha prevenido oportunamente que el presidente, al recibir la autorización congresional para celebrar un tratado comercial, pueda eventualmente modificarlo.

Se menciona un tratado similar de libre comercio, como es el que llevaron a cabo Canadá y Estados Unidos, para establecer una zona de libre comercio (19 U.S.C. Secc. 212 (e), nota 102 (e) (1988).

En cambio, y pese a su semejanza, no sucedió así con el TLC, por lo que no hay la menor duda que el presidente no tenía facultades para enmendarlo.

El señor Kantor pretendía justificarlo explicando que se trataba de "acuerdos de última hora", pero nunca aclaró por qué se firmaron fuera del término legal para ello.

Uno de los autores consultados, el profesor Erikson, afirma que en los acuerdos ejecutivos debe recabarse la autorización del Congreso para negociarlos y para concluirlos; esto es, que se distinguen la facultad pa-

47 Aparentemente existió otra carta fechada el 4 de noviembre de 1993, dirigida por el doctor Jaime Serra a su homólogo M. Kantor, cuyo texto es casi igual a la del día anterior, pero sin referirse a la eliminación del párrafo 16. Como ésta no fue presentada al Congreso norteamericano, no la incluimos en nuestro análisis. 
ra celebrarlos de la de su conclusión. ${ }^{48}$ No puede el presidente moverse a su antojo y discreción, so pena de que se invaliden sus actos.

El celo del Congreso, como se ha repetido, es claro y trata de evitar que el Ejecutivo evada su autoridad.

Inclusive se ha llegado a sostener que permitir estos acuerdos ejecutivos atentaría cada vez más seriamente el proceso democrático, pues se impediría la participación de los legisladores como representantes de los estados en asuntos que los afectarán. ${ }^{49}$

\section{Si la legitimidad de los acuerdos ejecutivos presidenciales es sin fundamento sólido, más delicados son cuando la materia es el comercio internacional}

En una reflexión necesaria, vemos que tradicionalmente estos acuerdos ejecutivos han sido utilizados en temas de alto contenido político, pero fundamentalmente en casos de guerra o bien de asuntos militares. En los últimos años se han extendido a problemas distintos, pero vinculados también de alguna forma con hechos bélicos, como han sido las reclamaciones por actos del Ejecutivo en contra de extranjeros.

Fue a partir de los años setenta cuando se tocó el tema del comercio internacional, y esto resulta delicado, pues, como se dijo, corresponde conforme a la Constitución exclusivamente al Congreso.

Esta práctica cada vez más preocupa a los defensores de la cláusula de los tratados, como la llamamos, máxime cuando se usa fuera de casos de guerra, o de emergencia nacional, del arreglo de reclamaciones o aun en el reconocimento de gobiernos extranjeros.

Como se ha visto, se pone en duda la legitimidad de los últimos y más importantes acuerdos, como son los asumidos en la Ronda Uruguay, la aceptación de la Organización Mundial de Comercio, el propio TLCAN y los acuerdos suplementarios.

Con mayor razón podemos considerar que las "cartas paralelas" no tienen mayor valor legal, pues carecen del menor sustento objetivo.

48 Erickson, Richard J., "The making of efective agreements by the United States Department of Defense. An agenda for progress”, B.U. International Law Journal, núm. 45, 1995, p. 13.

49 Weiss y Tribe opinan en este sentido. Ver Weiss, Jack S., "The approval of arms control agreements as congressional executive agreements", UCLA Law Review, USA, núm. 38, 1991, pp. 1533, 1554-1555; Tribe, H., "Taking text and structure seriously. The World Trade Organisation...", Hearing before the Senate. 103 Cong. 1994. 
Para regular las importaciones se requiere una ley aprobada por el Legislativo, por lo que las cartas en cuestión que expresamente fueron presentadas al Congreso están en el vacío legal y no tienen ninguna fuerza obligatoria. Para ilustrar lo anterior invocamos los casos siguientes: “United States vs. Yoshida Int'1. Inc. (526 F. 2d. 560, 571-83 (C.C.P.A, 1975)"; "Consumers Union of U.S. vs. Kissinger et al. 506 F. 2d. 136, 142-43 (D.C. Cir 1974)".

\section{E. Falta de notificación al GATT de la suscripción de las cartas paralelas}

El 29 de enero de 1993 los tres países signatarios del TLC notificaron formalmente al GATT que habían celebrado el acuerdo y que se enviaba para su conocimiento, acorde con el artículo XXIV, párrafo 7 (a) del Acuerdo General, una copia del texto y de los aranceles negociados y se depositó en el secretariado una copia para consulta de los interesados. ${ }^{50}$

En cambio, según fuentes consultadas, nunca se hicieron llegar los textos que modificaban al documento original.

Por lo tanto, tampoco existen para efectos legales, en los archivos del GATT, las cartas paralelas.

Esta falta de cumplimiento sólo tiene una explicación, y esta es su irregularidad.

Podemos formular las siguientes

\section{CONCLUSIONES}

Primera. El 4 de noviembre de 1993 el presidente William Clinton presentó al Congreso de los Estados Unidos, dos paquetes de documentos relacionados con el Tratado de Libre Comercio de América del Norte:

1. El primero contenía el texto y la legislación necesaria para su implementación.

2. El segundo, un conjunto de documentos que no requerían la aprobación formal del Congreso en número de seis, y aparecían en segundo término las "cartas paralelas" referentes al azúcar y a los edulcorantes. 
Segunda. Conforme a la clasificación formulada por el propio presidente Clinton, se distinguen acuerdos suplementarios, acuerdos, informes y cartas técnicas.

Tercera. El gobierno norteamericano puede celebrar, a través del Ejecutivo, diversos acuerdos internacionales, pero sólo los tratados aprobados por el Senado están contemplados en la Constitución.

Cuarta. De la revisión y opinión de precedentes y especialistas en la materia se concluye firmemente que las llamadas "cartas paralelas" se ubican como presidential executive agreements llamados también sole.

Quinta. Mediante este tipo de acuerdos se evade el rígido control del Senado, por lo que la ley de la materia regula desde 1974 las llamadas congresional executive agreements, que se ocupan del comercio internacional.

Sexta. Dado que la materia del citado comercio es facultad exclusiva del Congreso, se requiere una autorización previa para negociar cualquier convenio que afecte los aranceles, el cual deberá ser aprobado a su culminación.

Séptima. La negociación en cuestión tiene un término, a cuya conclusión se termina la facultad de ejercerla, utilizándose la figura denominada fast track.

Octava. En el caso del TLCAN, se siguió este sistema y su vigencia de negociación corrió del 1o. de mayo de 1991 al 31 de mayo de 1993.

Novena. Las cartas paralelas se fecharon el 3 de noviembre de 1993.

Décima. Por las múltiples razones y argumentos expuestos consideramos que las cartas paralelas carecen de validez legal.

Decimoprimera. Por lo tanto, de acuerdo con la práctica y el derecho norteamericanos, no se puede modificar el texto del TLC.

Decimosegunda. En cuanto a la situación en México, el TLCAN fue aprobado oportunamente por el Senado de la República, en uso de las facultades que le concede el artículo 76, fracción 1.

Decimotercera. Las "cartas paralelas" no se acompañaron al texto negociado por el Ejecutivo y aprobado por el Senado, por lo que son inexistentes.

Decimocuarta. Si se hubieran presentado tampoco tendrían valor, por las razones expuestas.

Decimoquinta. Tampoco se puede considerar que sean acuerdos intersecretariales, por no haberse respetado las formalidades requeridas por la Ley de Tratados. 
Decimosexta. Las disposiciones de la Convención de Viena, pese a no ser aplicables, por no ser parte los Estados Unidos, fueron analizadas, y conforme a ellas las cartas en cuestión tampoco tienen valor.

Decimoséptima. Se puede concluir finalmente que no hay preceptos legales nacionales de ambos países ni internacionales que doten de fuerza legal a los documentos en cuestión.

Por ende: el texto original del anexo 703.2, párrafos 15 y $16 \mathrm{del}$ TLCAN, permanece en la forma en que se negoció y aprobó por los países miembros del mismo, conserva toda su fuerza vinculatoria entre las partes.

\section{BIBLIOGRAFÍA}

ADAME GODDARD, Jorge, "El Tratado de Libre Comercio en el orden jurídico mexicano", en Witker, Jorge (coord.), El Tratado de Libre Comercio de América del Norte. Análisis, diagnóstico y propuestas jurídicos, México, IIJ-UNAM, 1993.

BERNAL, Carlos, "Los convenios ejecutivos ante el derecho constitucional e internacional", Jurídica, México, Universidad Iberoamericana, núm. 12, 1980.

CRUZ MIRAMONTES, Rodolfo, "Rechaza Washington la propuesta mexicana sobre la formación de un Tribunal Comercial, R. Cruz", El Financiero, México, 6 de marzo de 1992.

, El TLC: controversias, soluciones y otros temas conexos, México, McGraw-Hill, 1997.

, "Entorno jurídico del TLC", Panorama jurídico del Tratado de Libre Comercio, México, Universidad Iberoamericana, Departamento de Derecho, 1993, t. II.

—_, "Asilo y extradición. Derecho y práctica en México", El Foro, México, Órgano de la Barra Mexicana, Colegio de Abogados, núm. 32, 1973.

__ , "El caso Álvarez Machain", Ars Iuris, México, Universidad Panamericana, núm. 8, 1993.

_-_, La Ley norteamericana de Inmunidad del Estado Soberano de 1976, México, Instituto Mexicano de Comercio Exterior, 1981.

__, "Las comisiones fluviales internacionales y la Comisión Internacional de Límites y Aguas", Natural Resources Journal, Universidad de Nuevo México. 
ChARnOvitZ, Steve, "The NAFTA Environmental Side Agreements", International and Comparative Law Journal.

El Financiero, México, 6 de marzo de 1992.

FISHER, Louis, American Constitutional Law, McGraw-Hill, Georgetown University, 1995.

GARCIADIEGO, Javier et al., El TLC día a día, México, Miguel Ángel Porrúa, 1994.

GAZCón, Felipe, Reforma, México, 3 de septiembre de 1997, sección de Negocios.

GonZÁlEZ, Lourdes, El Financiero, México, sección Economía.

HALl, Kevin G., "U. S. and Mexico attempt to resolve sugar dispute", The Journal of Commerce, March 20, 1998.

JACKSON, John H. et al., Legal Problems of International Economic Relations, 3a. ed., West Publishing.

MENA, Yadira, El Economista, México, sección Industria y Comercio.

"Mexico may seek NAFTA panel on sugar Dispute with US, Dow Jones

News Wires", 9 de agosto de 1999.

ORTIZ AHLF, Loretta, Derecho internacional público, México, Harla, 1993.

Página web del secretariado del TLCAN: http//www.nafta-sec-alena.org/spanish/rules/ch20/ch20p. Htm

PALACIOS TREVIÑO, Jorge, Tratados: legislación y práctica en México, México, 1986.

POSADAS, Alejandro, “NAFTA'S Approval: A Story of Congress at Work...", LSA Journal of International and Comparative Law, volume 2, núm. 2, primavera de 1996.

PRIOL-VREJAN, Sandra Le, "The NAFTA Enviromental Side Agreement and the Power to Investigate Violations of Environmental Laws", Hobstra Law Review, núm. 23.

Rousseau, Charles, Derecho internacional público, Barcelona, Ariel, 1961.

SÁNCHEZ BRINGAS, Enrique, “Artículo 117”, Constitución Política de los Estados Unidos Mexicanos comentada, México, IIJ-UNAM, 1985.

SENADO DE LA REPÚBLICA, Tratados ratificados y convenios ejecutivos celebrados por México, México, 1972.

SEPÚlVEDA, César, Derecho internacional público, 18a. ed., México, Porrúa, 1997. 
SRE, Los convenios ejecutivos ante el derecho constitucional e internacional, México, Instituto Mexicano "Matías Romero" de Estudios Diplomáticos, s.a.

_- Los convenios ejecutivos ante el derecho constitucional e internacional, México, Instituto Mexicano "Matías Romero" de Estudios Diplomáticos, s.a.

StARKE, I. G., An Introduction to International Law, Gran Bretaña, Butterworths and Co., 1963.

VON BERTRAB, Hermann, El redescrubrimiento de América. Historia del TLC, México, Fondo de Cultura Económica, 1996.

WITKER, Jorge (coord.), El Tratado de Libre Comercio de América del Norte. Análisis, diagnóstico y propuestas jurídicos, México, IIJUNAM, 1993, t. I. 